\title{
EXPERIMENTALISMO E ALTERNATIVAS INSTITUCIONAIS: NOTAS ACERCA DA AÇÃO COLETIVA EM MIHAIL MANOILESCU, OLIVEIRA VIANNA E MANGABEIRA UNGER ${ }^{1}$
}

\author{
EXPERIMENTALISMO Y ALTERNATIVAS INSTITUCIONALES: NOTAS \\ ACERCA DE LA ACCIÓN COLECTIVA EN MIHAIL MANOILESCU, OLIVEIRA \\ VIANNA Y MANGABEIRA UNGER
}

\author{
EXPERIMENTALISM AND INSTITUTIONAL ALTERNATIVES: NOTES ON \\ COLLECTIVE ACTION IN MIHAIL MANOILESCU, OLIVEIRA VIANNA AND \\ MANGABEIRA UNGER
}

George Freitas Rosa de ARAUJO²

RESUMO: Retomamos panoramicamente autores afins ao experimentalismo político, às proposições de alternativas institucionais, relendo os pensamentos de Mihail Manoilescu, Oliveira Vianna e Mangabeira Unger no que concernem à ação coletiva de classe e/ou categoria econômica, especialmente corporativa, enquanto componentes de (re)construção sociais. Levantamos as seguintes hipóteses: (i) as proposições dos dois primeiros, apesar de sugerirem mudanças estruturais inventivas, mostrar-se-iam limitadas quanto à maximização da equidade econômica e social; (ii) e a conexão mais estreia entre democracia e equidade econômica seria construía, nas correntes experimentalistas atuais, por Unger. Concluímos que estes intelectuais criticaram o liberalismo político e econômico apresentando, pari passu, conteúdos programáticos explícitos e institucionalmente experimentalistas em suas épocas.

PALAVRAS-CHAVE: Alternativas institucionais. Experimentalismo político. Democracia.

RESUMEN: Esta investigación retoma a los autores filiados al experimentalismo político y a las proposiciones de alternativas institucionales, relando críticamente los pensamientos de Mihail Manoilescu, Oliveira Vianna y Mangabeira Unger en lo que concierne a la acción colectiva de clase y / o categoría económica, especialmente de carácter corporativo, como componentes de (re) construcción de nuevos regímenes políticos. Tenemos las siguientes hipótesis: (i) las proposiciones de los dos primeros, a pesar de sugerir cambios estructurales inventivos, se mostrarían limitadas desde el punto de vista de la maximización de la equidad económica y social, que se configuraría en un factor esencial en la construcción democrática; (ii) esta conexión más estrecha entre democracia y equidad económica sería construida por nuestro contemporáneo, Unger. Concluimos que los tres intelectuales

1 O presente artigo é uma versão revista, modificada e atualizada do trabalho intitulado "Experimentalismo político e alternativas institucionais: notas acerca da doutrina corporativista de Mihail Manoilescu, o caso brasileiro em Oliveira Vianna e a alternativa democrática em Mangabeira Unger", apresentado na "XI Semana de História Política - Relações de Poder: crise, democracia e possibilidades", realizado na Universidade do Estado do Rio de Janeiro (UERJ), em 2016, e publicado nos Anais da XI Semana de História Política, PPGH/UERJ, 2016. v. 1. p. 821-837.

${ }^{2}$ Universidade Federal Fluminense (Uff), Niterói - RJ - Brasil. Pesquisador no Laboratório de Estudos Republicanos (LER) do Departamento de Ciência Política. E-mail: george.freitas.araujo@outlook.com. 
criticaron el liberalismo político y económico presentando, pari pasu, contenidos programáticos explícitos e institucionalmente experimentalistas en sus respectivos y diferentes escenarios históricos.

PALABRAS CLAVE: Alternativas institucionales. Experimentalismo político. Democracia.

ABSTRACT: This research takes panoramically authors affiliated to political experimentation and the institutional alternative proposals, critically re-reading the thoughts of Mihail Manoilescu, Oliveira Vianna and Mangabeira Unger with concern the collective action class and / or economic category, especially corporatist nature, qua components of (re)building new political regimes. We suggest the following hypotheses: (i) the propositions of the first two authors, despite suggesting inventive structural changes, would be limited from the point of view of maximizing economic and social equity, which would be an essential factor in democratic construction; (ii) this connection between democracy and economic equity would be constructed by our contemporary, Unger. We conclude that the three intellectuals criticized the political and economic liberalism presenting pari passu, explicit contents and institutionally experimentalists in their respective and different historical scenarios.

KEYWORDS: Institutional alternatives. Political experimentalismo. Democracy.

\section{Introdução}

O pensamento social contemporâneo pode ser compreendido, panoramicamente, a partir de três tendências: (i) a racionalista - referenciada (re)interpretativamente no filósofo alemão Georg W. Friedrich Hegel (1770-1831) -, compreende o real como racional, de modo a perceber as transformações sociais como inevitáveis e necessárias. Áreas da economia, sociologia e ciência política hodiernas são influenciadas sobremaneira por este viés; (ii) A humanização, fundada na desilusão a respeito das promessas do igualitarismo liberal que propugna uma redistribuição marginal como o ápice de expectativas na política, fundando-se na premissa da necessidade de humanizar o mundo por meios impessoais, como o Estado compensador dos desajustes promovidos pelo mercado. Este viés percebeu amplo incremento na atualidade, e.g. através do foco central governamental em políticas públicas compensatórias que objetivam amainar as desigualdades mercadológicas; (iii) O subjetivismo, nascente na pós-modernidade, chama atenção para os aspetos sobremodo individuais na construção social, pretendendo erigir-se em crítica ao racionalismo. O resultado desta tendência é um escapismo do pensamento quanto ao real e às mudanças em escala, focando em projetos individuais em detrimento dos coletivos. As três tendências contemporâneas, para 
além dos contrastes, assemelham-se num ponto fulcral, relegam à margem a questão das transformações institucionais (TEIXEIRA, 2013).

Neste cenário do pensamento Ocidental, refletirmos centralmente em alternativas institucionais e nas formas de Direitos que as definem constitui um programa teórico e crítico à filosofia e à teoria política hegemônicas.

No presente trabalho, elencamos três autores filiados ao experimentalismo institucional, relendo comparativa e criticamente os pensamentos do romeno Mihail Manoilescu (1891-1950) e dos brasileiros Francisco José de Oliveira Vianna (1883-1951) e Roberto Mangabeira Unger (1947-) no que concernem ao papel da ação coletiva de classe e/ou categoria econômica, especialmente de cariz corporativa, no (re)construção das sociedades, com acento nas suas dimensões político-econômicas.

Esta seleção é informada pelas seguintes premissas: (i) Manoilescu é um dos principais intelectuais da corrente experimentalista do século XX no tocante a corporativismo, uma temática que transpassa o trabalho em tela; (ii) Vianna constituiu-se num dos autores centrais de reapropriação inventiva do corporativismo no Brasil e (iii) Unger traduz-se num dos intelectuais fundamentais do experimentalismo institucional e da sua relação programática intrínseca com coletividades econômicas, revisitando criticamente a doutrina corporativista, que percebeu seu auge e declínio no século XX. Os três autores afinam-se genericamente em críticas negativas aos liberalismos político e econômico, por outro lado distanciam-se em diversos outros aspectos, tanto nos diagnósticos quanto nos prognósticos institucionais.

A princípio, sugerimos as seguintes hipóteses: (i) as proposições institucionais de Manoilescu e Vianna, apesar de sugerirem mudanças estruturais inventivas e radicais, mostrar-se-iam limitadas do ponto de vista da maximização da equidade econômica e social, que se configuraria em fator essencial na construção democrática; (ii) esta conexão mais estreia entre democracia e equidade econômica seria construía singular e densamente, na corrente dos experimentalistas institucionais, por nosso contemporâneo, Unger.

\section{Experimentalismo e alternativas institucionais no século XX: Mihail Manoilescu e o Século do Corporativismo}

O romeno Mihail Manoilescu é considerado um dos mais expoentes teóricodoutrinários do corporativismo no plano internacional, sendo (re)apropriado em regimes políticos diversos, seja no que concerne às corporações propriamente tidas seja nas suas 
elaborações em defesa do protecionismo econômico. No Brasil, influenciou consideravelmente os debates políticos e econômicos da primeira metade do século $\mathrm{XX}^{3}$. Uma de suas publicações mais conhecidas é intitulada de "O século do corporativismo", editada originalmente em 1934 e considerada referência básica desta doutrina. Nela, Manoilescu discorre acerca da importância do que considerava ser uma das mais relevantes (re)invenções do século XX, a corporação.

Uma das mais conhecidas expressões de Mihail Manoilescu provém do livro supracitado: "O século vinte será o século do corporativismo assim como o dezenove foi o século do liberalismo". Mesma frase que serve de epígrafe ao texto de Philippe C. Schmitter (1974), “Still the century of corporatism?", tido como um dos mais relevantes pesquisadores do corporativismo na atualidade.

Faz-se mister a seguinte questão: Qual corporativismo estamos tratando? Quando tratamos de corporativismo, estamos a referenciar o 'moderno corporativismo', associado ao Estado moderno, com características que serão explicitadas em seguida, diferenciando-se do corporativismo tal qual no ancien régime, particularizado, por exemplo, pelas 'corporações de ofício'.

Por que desta ênfase corporativista? O contexto histórico no qual Manoilescu escreveu sua obra pode ser, grosso modo, sintetizado por alguns 'marcos', a saber: 1917, Revolução Bolchevique na Rússia; 1922, golpe de Mussolini na Itália e 1933, quando Adolf Hitler foi nomeado chanceler da Alemanha. Em todos estes casos, instauraram-se um partido único. A Primeira Guerra Mundial pode ser entendida como sinal da crise da economia liberal, numa disputa por mercados. O período Entreguerras foi marcado pelo crescimento do corporativismo como forma de organização da sociedade, por um concomitante enfraquecimento da liberal-democracia e crescimento da presença estatal na economia, mesmo em países de maior desenvolvimento relativo.

A questão do partido único foi também tratada por Manoilescu paradigmática e centralmente em seu escrito "Le Parti Unique" (1937). As corporações e o partido único são

${ }^{3}$ Neste sentido, é bastante representativo o empenho do industrial, político e economista Roberto Cochrane Simonsen (1889-1948), uma das principais referências no debate econômico e na liderança empresarial da época - e.g. iniciou presidência da Federação das Indústrias do Estado de São Paulo (FIESP) em 1937 - na publicação, pelo Centro das Indústrias do Estado de São Paulo, do livro Teoria do Protecionismo e da Permuta Internacional, de Manoilescu (1931). Cf. Bielschowsky (2000). A citada publicação do político romeno foi atualmente reeditada no Brasil, em 2011, pela Cepax Dei. 
entendidos como as principais invenções políticas, no plano institucional, do último findo século 4 .

Para Manoilescu, existiriam três tipos de corporativismo. O anunciado com mais destaque foi o "corporativismo puro", no qual a legitimidade estatal residiria nas próprias corporações. Em segundo lugar, haveria o "corporativismo subordinado", no qual a legitimidade estatal fundar-se-ia em outras bases sociais, para além das corporações; finalmente, poderia haver um tipo "misto", que mesclaria as particularidades dos dois primeiros casos. Salienta-se que esta classificação seria um tipo ideal com fins analítico e propositivos a partir do qual as sociedades poderiam ser observadas.

Uma noção importante é a ideia de 'função', quer dizer, as corporações deveriam existir porque teriam uma função sociopolítica a exercer e porque, reciprocamente, responderiam às necessidades sociais específicas no espaço-tempo determinado.

O Estado, no corporativismo puro, é entendido como uma corporação num duplo sentido funcional: por um lado exerceria funções particulares, tal como qualquer outra corporação e, por outro, seria uma super corporação ao exercer a função de coordenação do regime político. Emerge, portanto, baseado socialmente nas corporações, um Estado corporativo, ideal para Manoilescu no sentido de atender as supostas necessidades das nações de sua época (MANOILESCU, 1938).

O ideal de Estado corporativo de Manoilescu é o da descentralização funcional, ou seja, estaria a cargo das corporações determinadas funções estatais, no plano administrativo ${ }^{5}$. Esta descentralização tornaria o Estado, aos seus termos, 'plural', voltado para atender às pretensas necessidades nacionais (MANOILESCU, 1938).

No corporativismo subordinado, a fonte de legitimidade do Estado, ou mais especificamente do Legislativo, originar-se-ia do sufrágio universal - entendido como resquício liberal -, gerando um atrito problemático no sentido da formação de um Parlamento Corporativo autônomo, ou seja, aquele fundado nas corporações. Manoilescu secundariza este tipo de corporativismo, pois teria de conviver com o difícil legado liberal do sistema partidário e do sufrágio universal (MANOILESCU, 1938).

Seguindo na esteira deste raciocínio, clareia-se o motivo de Manoilescu igualmente margear o corporativismo misto, afinal se um Parlamento eleito por sufrágio universal não

${ }^{4}$ O século XX para o romeno iniciar-se-ia em 1918, momento no qual sua perspectiva corporativa estava alcançando maior densidade doutrinária e experimental no cenário político e econômico internacional.

${ }^{5}$ Mesmo princípio a ser apropriado positivamente por Vianna em sua proposição de cariz corporativa para o Brasil. Trata-se de certa pulverização de prerrogativas estatais para coletividades supostamente representativas de dimensões estruturais das sociedades, como na economia com as corporações classistas. 
seria a alternativa institucional tida por ideal, não refletindo os interesses nacionais, tampouco seria produtivo a convivência de um Parlamento eleito por sufrágio universal e outro estabelecido a partir da representação corporativa (MANOILESCU, 1938).

Um princípio orientador das elaborações doutrinárias de Manoilescu é a precaução em evitar generalizar experiências históricas corporativas determinadas para todas as sociedades. Os delineamentos que concede ao seu construto teórico-doutrinário corporativo são mais abstratos a fim capacitá-lo a funcionar adequadamente em qualquer sociedade, independente das suas particularidades, que seriam assimiláveis às práticas corporativas. Trata-se de um tipo ideal propositivo que mencionamos outrora.

O Estado deveria estar sujeito, na ótica de Manoilescu, aos interesses nacionais de modo a assentar-se nas corporações como meio de organizar a nação. Deveria possuir um caráter impositivo e normatizador no sentido dos imperativos nacionais. Entretanto, em contraste com a experiência fascista, Manoilescu não pretendia priorizar a função econômica frente às outras, mas, contrariamente, a hierarquização das funções corporativas definir-se-ia em função das especificidades locais (MANOILESCU, 1938).

Visando a não priorização da função econômica num Estado corporativo, diferencia conceitualmente a corporação do sindicado: enquanto aquele teria um escopo mais extenso na medida das necessidades funcionais da nação, o segundo diria respeito apenas à economia e à representação da categoria que a constitui. Em outras palavras, enquanto os sindicatos preocupar-se-iam com os interesses de um grupo, as corporações estariam voltadas aos interesses nacionais. Ambos não se anulariam, mas se complementariam, os sindicatos poderiam compor a corporação (MANOILESCU, 1938, p. 127).

Pretendendo dirimir os conflitos entre capital e trabalho, Manoilescu propõe a convivência, numa mesma corporação, dos sindicatos dos operários e dos patrões, de tal forma que ambos estivessem imersos numa mesma identidade. O corporativismo propugnavase como solução à Questão Social.

\section{Experimentalismo e alternativas institucionais no século $\mathrm{XX}$ : corporativismo à brasileira - o caso Oliveira Vianna}

Para o fluminense de Saquarema Oliveira Vianna, a nossa história social e política seria marcada pela formação clânica, gestada nos grandes potentados rurais e que se cristalizariam em nossas instituições. Esta 'atomicidade' característica do povo brasileiro, estender-se-ia ao longo da nossa história e deveria ser levada em consideração quando da 
formação de leis e políticas públicas. A crítica negativa à importação de ideias estrangeiras, seguindo a filiação explícita a Alberto Torres - um dos seus principais predecessores intelectuais -, é mais um componente argumentativo do seu pensamento, desde os primeiros escritos até os publicados postumamente.

A democracia brasileira tal como proposta pelo fluminense não deveria ser importada de outras sociedades, antes precisaria ser pensada a partir de questões supostamente específicas ao nosso povo. Lembremos que a crítica foi à importação pura e simples de organizações jurídicas e instituições, entretanto poderíamos importar soluções estrangeiras e/ou adaptá-las, se os problemas de que tratam fossem os mesmos ou similares aos vivenciados por nós (VIANNA, 1943, 1951, 1983, 1999, 2005).

Inserido num cenário nacional e internacional de crítica ao liberalismo, o fluminense acessou a chamada tradição do pensamento autoritário brasileiro como uma de suas fontes para elaborar soluções para a Questão Social. A Doutrina Social da Igreja (DSI) e as novas experiências de caráter corporativista que pululavam no Velho Mundo, constituíram outras fortes influências. Neste contexto histórico, Oliveira Vianna acreditava que a Questão Social seria um problema universal ${ }^{6}$.

Como não possuiríamos problemas de excesso de população ou carência de espaço, não estabeleceríamos uma sociabilidade fundada na luta de classes. Para Oliveira Vianna, as saídas socialistas e comunistas foram deslocadas do campo de possibilidades para a solução da Questão Social entre nós. O autor argumentava que, devido às "condições excepcionais" nas quais viveríamos, e.g. a abundância de recursos naturais, a solução da Questão Social seria a desproletarização dos que "não possuem" sem, contudo, proletarizar "os que possuem". Isto ocorreria pela generalização da propriedade privada.

Oliveira Vianna argumentava que, tendo em vista nossa mentalidade tendencialmente clânica, a representação partidária não se adequaria à nossa "realidade". O "povo-massa" estaria "diluído" nos partidos existentes, de modo que o simples sufrágio universal aliado a eleições periódicas não seria suficiente para desenvolver, no povo, a prevalência, no espaço público, dos interesses coletivos frente aos privatismos que nos seriam peculiares.

Dentre as críticas ao modelo econômico liberal, a presença do pensamento católico, especialmente da Doutrina Social da Igreja Católica, fez-se evidente na obra de Oliveira Vianna. Neste âmbito, retomamos uma das suas ideias mais basilares: a força do Estado

${ }^{6}$ A Questão Social fora entendida por Vianna como conflito, aos seus termos, dos "os que possuem" e com "os que não possuem”, dos proprietários e dos não proprietários.

Rev. Sem Aspas, Araraquara, v. 6, n. 2, p. 110-124, jul./dez., 2017. e-ISSN 2358-4238 
poderia romper com o princípio da pura liberdade de mercado, amparando o trabalhador e elevando-o não apenas em suas condições materiais, mas também morais.

Para Oliveira Vianna, a organização corporativo-sindical que deveríamos adotar não teria apenas o papel de tutela, mas também se constituiria numa ferramenta pedagógica do nosso povo, orientando-o no sentido da participação nas atividades do Estado via representação classista e visando os interesses nacionais.

A organização do povo não se daria apenas por um novo arranjo institucional, cristalizado juridicamente nas leis, antes seria um meio de propiciar o desenvolvimento de novas mentalidades ligadas à maior preocupação com os interesses grupais.

Neste sentido, os sindicatos formariam, para o autor fluminense, pequenas assembleias nas quais os temas relativos aos interesses das suas respectivas coletividades profissionais seriam debatidos. Estas assembleias constituir-se-iam em pequenas democracias de participação direta dos seus membros. A participação cidadã por meio de coletividades profissionais seria um prefigurador de um Estado-Nação fortalecido corporativamente.

No que respeita à crítica de Oliveira Vianna a nossa descentralização republicana de caráter liberal, salientamos a distinção entre a descentralização federativa e territorial e a descentralização de funções ou de serviços. O saquaremense criticou a descentralização federativa, fundada no princípio da autonomia administrativa territorial, enfatizando a necessidade de adotarmos, em semelhança à proposta de Manoilescu, a descentralização de funções em prol das coletividades corporativas, ou seja, o Estado concederia determinadas prerrogativas ao sindicato, como a de legiferar acerca de temas de interesse específico de uma dada classe profissional. Por conseguinte, as assembleias sindicais teriam um caráter parlamentar, esmaecendo o papel legislador e representacional do Parlamento propriamente dito. Para a consecução da tarefa pedagógica das organizações corporativas, consideradas por Oliveira Vianna como mais legitimamente democráticas do que as liberais, não seria suficiente a reunião do povo em assembleias sindicais, sendo necessário formar elites ${ }^{7}$ que orientassem o povo no caminho dos interesses nacionais.

Vianna apropriou-se inventivamente dos diagnósticos e prognósticos de Mihail Manoilescu, aproximando-se em aspectos mais genéricos como a crítica aos liberalismos

\footnotetext{
${ }^{7}$ Por elite, Vianna entendia não necessariamente os possuidores de maior quantitativo de bens materiais, mas os considerados "melhores" em sua categoria, seja ela intelectual e/ou profissional. Estes homens seriam os que melhor estariam preparados para representar sua categoria e exercer cargos eletivos estatais. A "classe dirigente" deveria ser formada, pela nossa elite. O problema democrático, entre nós, não seria o governo de poucos, de uma oligarquia, mas sim o disciplinamento/reeducação desta oligarquia no sentido capacitá-la ao exercício do seu papel pedagógico e dirigente, enfim, aos termos de Oliveira Vianna, deveríamos formar uma "oligarquia esclarecida" (VIANNA, v. I, 1999).
} 
político e econômicos por meio de maior presença de um Estado de matriz corporativa na sociedade, a ênfase em orientadores privilegiados como ordem e nação em detrimento do indivíduo, e da valorização do papel das ações coletivas, corporativistas, na construção civilizacional da sua época. Distanciaram-se em diversos pontos dos quais salientamos um dos mais importantes, o romeno conferia ao Partido Único função fundamental e tendencialmente universal na construção das novas instituições corporativas ao passo que o brasileiro de Saquarema relativizou sobremodo este tipo de organização política, ao menos em sua aplicabilidade ao Brasil.

\section{Experimentalismo e alternativas institucionais na atualidade: Mangabeira Unger e a radicalidade democrática}

$\mathrm{Na}$ senda do experimentalismo democrático e da construção de alternativas institucionais, Unger, em "O direito e o futuro da democracia" (2004), pretende encontrar o ponto de coincidência democrática, quer dizer, a interação entre progresso material e independência individual, acentuando a equidade econômico-social. Este momento ótimo seria encontrado por meio do experimentalismo num processo de aprendizagem em coletividades.

Um dos obstáculos ao experimentalismo democrático seria o "fetichismo institucional", que diria respeito à crença na qual as instituições abstratas como a democracia política, o capitalismo e a sociedade civil livre possuiriam um único significado universal. Este fetichismo permearia a cultura contemporânea e mais especificamente as ciências sociais. Afastarmo-nos deste fetichismo requereria crítica e engajamento dos cientistas sociais à causa democrática (UNGER, 2004, p. 17).

O fetichismo institucional encontraria ressonância na ciência política quando de seu afastamento em relação à filosofia, em outras palavras, ao pretender construir um gap entre princípios prescritivos explícitos e a elaboração normativa de ideias e experiências institucionais (UNGER, 2004). Este caminho de afastamento da ciência social em relação à filosofia, entre "ciência" pretensamente impessoal e conteúdo programático explícito, foi longamente aborda por autores como Peter Winch e Sheldon Wolin.

Os países mais bem sucessivos no que concerne ao desenvolvimento econômico e autoafirmativo seriam os que mais exercitariam o experimentalismo institucional. O Brasil, por exemplo, ao conciliar mais liberdade dos sindicatos aos Estados com o princípio da 
sindicalização automática e ampla dos trabalhadores poderia ser um "germe" (ALBUQUERQUE, 2010) ${ }^{8}$ de experimentalismo democrático (UNGER, 2004, p. 18).

Atualmente, a simples oposição estatismo versus privatismo estaria em declínio. $\mathrm{O}$ conflito ideológico estaria mudando para formas alternativas de pluralismo econômico, social e político. A premissa é a de que as sociedades livres e democráticas poderiam perceber várias formas institucionais. Contudo, haveria uma exaustão em formular alternativas confiáveis ao (neo)liberalismo (UNGER, 1999, p. 11).

O experimentalismo democrático ungeriano uniria duas esperanças e um ação: (i) $1^{\text {a }}$ esperança, como apontamos antes, é encontrar a convergência entre as condições do progresso material - crescimento econômico e inovação tecnológica e médica - e as necessidades de emancipação individual - libertação das amarras individuais em relação aos papéis sociais, divisões e hierarquias, especialmente relativas às vantagens socioeconômicas herdadas; (ii) a $2^{\mathrm{a}}$ é perseguir o ponto de interseção do progresso-emancipação individual atendendo aos desejos dos "homens e mulheres comuns" de acordo com a maneira como eles(as) entendem suas próprias necessidades; (iii) e a ação diz respeito ao ajuste motivado, sustentado e cumulativo das estruturas sociais. Ideias, interesses e práticas institucionais estariam interrelacionadas umbilicalmente. Ao colocarmos em questão as instituições poderíamos visualizar suas falhas ocultas. Não poderíamos separar, como a teoria política hegemônica, um momento de definição dos interesses e ideias e outro posterior de construção de instituições como numa engenharia institucional (UNGER, 1999, p. 13-19).

A referida ação funda-se na ideia de "reforma radical": pretende transformar as estruturas sociais que formam as instituições e crenças. É "reforma" porque lida separadamente com as estruturas institucionais, amparando-se na premissa de que estas não são indissociáveis e podem ser transformadas separada e gradativamente nas partes que a compõe. É "radical” porque propõe alterar os fundamentos contextuais que informam as instituições e crenças vigentes (UNGER, 1999, p. 23).

As mobilizações contemporâneas nas democracias industriais ocidentais de maior magnitude têm sido empreendidas fora do âmbito partidário, como por meio dos sindicatos e organizações ligadas a defesa de minorias e interesses outros não encampados com maior

${ }^{8}$ Utilizamos o termo "germe" tal como entendido por Eduardo da Motta e Albuquerque (2010), em A Agenda Rosdolsky, no qual aponta sinais de um uma transformação estrutural e institucional de ampla magnitude no contexto institucional vigente. Nesta publicação, Albuquerque retoma os estudos de Roman Rosdolsky (18981967) a respeito das transformações do capitalismo à luz dos escritos marxianos $O$ Capital e Grundrisse, objetivando observar o prelúdio parcial indicativo da transição do capitalismo ao socialismo. A partir desta retomada, Albuquerque pretende identificar o que seriam os "germes" do socialismo na atualidade e propor uma "agenda" programática visando às transformações radicais. Assim como Unger, Albuquerque entende que a história é aberta, os “germes” não são inelutáveis ou representam uma evolução necessária. 
vivacidade pelo poder público. Para além da mobilização, a direção tomada deveria seguir os caminhos de construção de uma "democracia empoderada", quer dizer, criticar os alicerces institucionais da democracia representativa e do mercado atuais, que não se mostrariam eficientes para suprir os objetivos doutrinários propostos. Esta crítica extrapartidária teria seu correlato no interior do sistema partidário, como na criação de uma nova organização partidária e/ou reorganização de uma já existente, engajada no programa da transformação revolucionária (UNGER, 1997).

Em países de Estado historicamente forte, a burocracia em seu patamar de base constituiria um recurso flutuante em potencial e poderia ser engajado nas causas da democracia empoderada e utilizar os recursos estatais para outros fins que os previamente estipulados. Exemplo: em países latino-americanos, setores como a agricultura frequentemente são auxiliados por funcionários públicos e sindicatos informados por uma conduta que visa à harmonia social ${ }^{10}$. Parcela dos funcionários desta burocracia poderia ser engajada à causa democrática de forma a utilizar os recursos que lhe são oferecidos de maneiras diversas à letra legal ${ }^{11}$.

Os sindicatos - recurso privilegiado da ação coletiva de classe e/ou categoria econômica -, que seriam tendencialmente oriundos, na Latino-América, de governos “autoritários", seriam informados por instituições que visam à manutenção do contexto formador em voga. Entretanto, uma vez estabelecidos, poderiam ser úteis como recurso mobilizador para a causa da democracia empoderada.

Deveríamos, para Unger, considerar a lógica dos interesses de coletivos, evitando-se, toda via, retraçar entrincheiramentos posições tal como visualiza (i) no marxismo ortodoxo ${ }^{12}$ que entenderia as inevitabilidades das contradições de classe configurando apenas uma alternativa social possível - e da ciência social positiva - ainda que entenda as ambiguidades dos interesses de classe, não conseguiria lidar com a ruptura da ordem estabelecida, evitandoa de várias formas. Precisaríamos compreender os conflitos de interesses coletivos a partir das suas limitações e ambivalências contextuais visando estabelecer estratégias que seriam

\footnotetext{
${ }^{9}$ Tradução do original em inglês: Empowered Democracy.

${ }^{10}$ Lembremos que os sindicatos no Brasil são instituições coletivas de categoria profissional que, atualmente, revestem-se de certo caráter corporativo tal como preconizados e parcialmente implementados nos governos de Getúlio Vargas e, intelectualmente, por Oliveira Vianna e sua reapropriação da doutrina corporativista de Mihail Manoilescu.

${ }^{11}$ Unger propõe radicalizar a estrutura sindical-corporativa, como a brasileira, no sentido de maior equidade socioeconômica a partir de instituições coletivas de categorias econômicas originalmente inventadas e implementadas, em nosso caso, especialmente após Vargas, visando a "paz social".

12 Unger desenvolve, com pretensão de contraste, a ideia de "contexto formador" como alternativa a ideia de "modo de produção". O primeiro diferir-se-ia do segundo ao entender as estruturas sociais como divisíveis e ao negar a ideia de "sistemas indivisíveis" regido por leis inevitáveis.
} 
identificadas positivamente pelos grupos de interesses visados pelo ativista da democracia empoderada (UNGER, 1997).

À medida que os conflitos fossem acirrados, pensa Unger, as identidades grupais e institucionais perderiam aderência aos interesses almejados e novas instituições precisam ser vivenciadas. Neste momento, os interesses precisariam ser redefinidos de forma a transcender as trincheiras de classe e de categoria sociais. $\mathrm{O}$ ativista ${ }^{13}$ deveria objetivar não a substituição de um interesse coletivo por outro - e.g. como propugnariam os intelectuais informados pela doutrina corporativa - mas ir além da subjugação da sociedade pelos interesses de grupos específicos.

Esta discussão subjaz as três teses da teoria social explicativa de Politics: (i) existiria uma associação entre o desenvolvimento de atividades experimentais e a invenção institucional que restringiria os constrangimentos a uma organização trabalhista preestabelecida. Em outras palavras, médias crises orientadas em direção à democracia empoderada engendrariam, gradativamente, condições mais favoráveis ao desenvolvimento do programa em causa em larga escala. (ii) Com relação aos conflitos de médio porte, se, por um lado, teriam seu escopo de soluções restringido pelo contexto formador, por outro o conjunto de soluções não seriam pré-definidos de forma que os recursos alternativos respeitantes à riqueza, poder e prestígio poderiam ser mobilizados e adaptados aos interesses da causa. (iii) Haveria uma relação inversa entre a contribuição de uma ordem institucional transformadora radical e a sua aceitabilidade, as transformações em direção à democracia radical não percorreriam uma senda tranquila por colidirem com interesses grupais estabelecidos. (UNGER, 1997).

Do ponto de vista econômico, a democracia empoderada requeria profunda transformação do edifício institucional liberal, sustentado na ideia de propriedade privada unitária, prognosticando um Estado com forte afluxo de capitais, de modo a ensejar o movimento democratizante radical simultaneamente à resolução de problemas econômicos que constrangeriam o processo transformador (UNGER, 1997).

$13 \mathrm{O}$ ativista da causa democrática precisaria estar atento às oportunidades de transformação da ordem institucional mesmo nos momentos de aparente 'paz social'. Algumas oportunidades são traçadas por Unger, como nos conflituosos objetivos de obtenção de privilégios governamentais por setores privados. Pequenas desestabilizações estariam presentes e poderiam ser utilizadas em prol do programa democrático de forma a conseguir redefinir os interesses em jogo, mudando, igualmente, as condições de sustentação dos contextos formadores. Outra manifestação de oportunidade residiria nos abalos constantes que os governos e a sociedade mais ampla viveriam ao tentarem readequar os conflitos econômicos ou militares à ordem institucional vigente. Um ativista reformador radical objetivaria, na contramão do gerenciador de crises conservador - e.g. os informados pelo corporativismo -, potencializar e acirra as disputas, expandindo-as no sentido do programa transformador (UNGER, 1997). 
Ainda com relação às propostas programáticas ungerianas, chamamos a atenção para a ideia de sindicalização generalizada dos trabalhadores, desempregados e pequenos empresários de modo à pretensamente garantir maior representação da sociedade como um todo, diminuindo a distância entre "incluídos" e "excluídos", "vanguarda" e "retaguarda" dualismo econômico. No desenvolvimento do experimentalismo democrático, os sindicatos deveriam ceder lugar às transformações mais profundas na democratização da economia de mercado com o desenvolvimento da herança social - a herança seria da sociedade e não dependeria da origem familiar de forma a possibilitar a todos as condições básicas de desenvolvimento individual - e a descentralização do acesso ao capital produtivo.

Unger propõe mecanismos institucionais que diminuiriam a distância entre a inovação e a cooperação de modo a evitar que o entrincheiramento de posições grupais, a seu ver como as corporativas, impeçam a inovação. A participação trabalhista nos lucros seria um meio de caminhar neste sentido (UNGER, 1999).

Unger critica a sindicalização voluntária, informada pelo contratualismo liberal, como forma de organização da sociedade civil uma vez que aumentaria o vácuo entre as divisões estabelecidas dos trabalhadores, e.g. entre os mais e menos qualificados. Em contraste, Unger positiva, ao menos como passo inicial, um sistema de direitos trabalhistas no qual haja combinação do voluntarismo contratualista e a organização corporativo-sindical de forma a resultar numa sindicalização automática geral de acordo com a indústria de trabalho, mas sem a tutela governamental. Uma radicalização dos modelos proposto por Manoilescu e Oliveira Vianna visando objetivos opostos.

A construção de uma socialdemocracia ampliada seria, segundo Unger, facilitada pela organização prévia da sociedade civil de acordo com a economia política corporativa uma vez que encontraria trabalhadores e empresários organizados em centros de negociação socioeconômica e aceitação de intervenção estatal nas estratégias de desenvolvimento econômico. As suas vantagens, porém, seriam transitórias uma vez que as garantias das coletividades estabelecidas tornar-se-iam direitos adquiridos, situação que, na ótica ungeriana, reconfiguraria a constelação de privilégios. A socialdemocracia ampliada agiria como antídoto ao entrincheiramento de interesses grupais (UNGER, 1999, p. 172-3).

\section{Considerações finais}

Concluímos que Manoilescu, Vianna e Unger criticaram o liberalismo político e econômico apresentando, pari passu, conteúdos programáticos explícitos e institucionalmente 
experimentalistas em seus respectivos e diferentes cenários históricos. Os diagnósticos e prognósticos de Manoilescu e Vianna, todavia, não centralizam a equidade econômica como fator essencial em suas propostas alternativas ao liberalismo, lacuna preenchida, nas correntes de intelectuais experimentalistas hodiernos, especialmente por Unger.

A atualidade temática abordada reside em dois fatores: (i) iluminar criticamente a experimentação política brasileira de caráter corporativo e (ii) retomar uma tradição de pensamento de alternativas institucionais programáticas que enriqueça o debate acadêmico no que respeita à proposição de outros e novos mundos possíveis e alternativos ao status quo institucional.

Entre divergências e convergências abstratas, chamamos a atenção para a importância de pensarmos alternativas institucionais nos contextos informadores em que vivemos. O aperfeiçoamento democrático é um processo longo e gradual. Imaginar o próximo passo deste caminho constitui ação importante na construção de novos arcabouços no plano do conhecimento que informarão inovações institucionais e reconfiguração os contextos informadores da nossa época.

\section{REFERÊNCIAS}

ALBUQUERQUE, Eduardo M. A Agenda Rosdolsky. 2010. 224 f. Tese (Professor Titular em Ciências Econômicas) - Departamento de Ciências Econômicas, Universidade Federal de Minas Gerais, Belo Horizonte, 2010.

BIELSCHOWSKY, Ricardo. Pensamento econômico brasileiro: o ciclo ideológico do desenvolvimentismo. Rio de Janeiro: Contraponto, 2000.

MANOILESCU, Mihail. Le parti unique: institution politique des regimes nouveaux. Paris: LES OEUVRES FRANÇAISES, 1937.

MANOILESCU, Mihail. O século do corporativismo: doutrina do corporativismo integral e puro. Trad. de Azevedo Amaral. Rio de Janeiro: JOSÉ OLYMPIO, $1938 .{ }^{14}$

TEIXEIRA, Carlos S. Filosofia Política e Experimentalismo Democrático: Alternativa para a Realização da Justiça. In: SIMPÓSIO INTERNACIONAL DE JUSTIÇA, n. 6, 2013, Porto Alegre. Anais do VI Simpósio Internacional de Justiça. Porto Alegre: PUC-RS, 2013. v. 1, p. 55-78.

UNGER, Mangabeira. Politics: the central texts. London: VERSO, 1997.

14 Tradução brasileira do original intitulado Le Siècle du Corporatisme: doctrine du corporatisme integral et pur, publicado pela parisiense Félix Alcan nos anos de 1934 e 1936. 
UNGER, Mangabeira. Democracia Realizada: A Alternativa Progressista (1998). Trad. De Carlos Graieb et al. São Paulo: Boitempo, 1999. ${ }^{15}$

UNGER, Mangabeira. O Direito e o Futuro da Democracia (1996). Trad. de Caio Farah Rodriguez e Marcia Soares Grandchamp. São Paulo: Boitempo, 2004. ${ }^{16}$

VIANNA, Oliveira. Problemas de direito corporativo (1938). $2^{\mathrm{a}}$ ed. Rio de Janeiro: Câmara dos Deputados, Coordenação de Publicações, 1983. (Biblioteca do pensamento político republicano, 16)

VIANNA, Oliveira. Problemas de direito sindical. Rio de Janeiro: Max Limonad, 1943. (Coleção de direito do trabalho, 1)

VIANNA, Oliveira. Direito do trabalho e democracia social: o problema da incorporação do trabalhador no Estado. Rio de Janeiro: José Olympio, 1951.

VIANNA, Oliveira. Instituições políticas brasileiras. (1949). Brasília: Conselho Editorial do Senado Federal, 1999, 2 vols. (Coleção biblioteca básica brasileira) ${ }^{17}$

VIANNA, Oliveira. Populações meridionais do Brasil (1920). Brasília: Conselho Editorial do Senado Federal, 2005, vol. I. (Edições do Senado Federal, 27)

WINCH, Peter. The Idea of a Social Science and its Relation to Philosophy. $2^{\text {nd }}$ ed. London: Routledge, 1990.

WOLIN, Sheldon. La teoría política como vocación. Foro Interno: Anuario de Teoría Política, Madrid, n. 11, p. 193-234, nov. 2011.

\section{Como referenciar este artigo}

ARAUJO, George F. R. Experimentalismo e Alternativas Institucionais: notas acerca da ação coletiva em Mihail Manoilescu, Oliveira Vianna e Mangabeira Unger. Rev. Sem Aspas, Araraquara, v. 6, n. 2, p. 110-124, jul./dez., 2017. E-ISSN: 2358-4238.

Submetido em: 25/10/2017

Aprovado em: 04/12/2017

15 Tradução brasileira do original em inglês sob o título Democracy Realized: The Progressive Alternative, publicado pela VERSO em 1998.

16 Tradução brasileira do original em inglês intitulado What Should Legal Analysis Become? Publicado pela VERSO em 1996.

17 O Conselho Editorial do Senado Federal reuniu em uma única brochura os dois volumes, publicados originalmente em brochuras separadas sob os seguintes (sub)títulos: vol. I - Instituições Políticas Brasileiras: Fundamentos Sociais do Estado: Direito Público e Cultura e vol. II - Instituições Políticas Brasileiras: Metodologia do Direito Público: Os problemas brasileiros da Ciência Política. Ambos editados originalmente pela José Olympio em 1949. 